\title{
A Decision Model For Contracting Helpdesk Services
}

Meg Murray, Kennesaw State University, USA

Joy Young, Kennesaw State University, USA

\begin{abstract}
Contractual helpdesk services, also known as call center outsourcing is a growing industry. Helpdesk solutions, which offer customer service to consumers who have an issue, problem or concern, are an integral part of many organizations' wider service function. For smaller companies, outsourcing helpdesk services is becoming more and more popular given the technical expertise and high investment costs required to develop, implement and maintain the infrastructure needed to support these services. Contracting for helpdesk services helps to alleviate smaller companies from concerns with technical issues, retaining employees dedicated to continuous research on the value proposition of emerging products or services, and in some cases, the need for hiring additional staff. While the basic principles for negotiating an outsourcing contract apply, this paper explores the special considerations pertinent to contracting helpdesk services. These include determining an optimal solution by mapping business requirements to specific call center resource options, determining the optimal call routing structure given budgetary considerations and understanding technical problems associated with the call center environment and developing a satisficing plan to address problems should they occur. As the technologies, including telecommunications and call routing options, that form the basis of helpdesk services evolve, so does the importance of helpdesk services as they move from cost centers to profit generating ventures.
\end{abstract}

Keywords: Helpdesk, telephony, contractual helpdesk service, outsourced helpdesk services, call center

\section{INTRODUCTION}

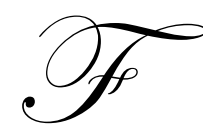

or some time now, companies have been using helpdesk services to provide a centralized support system to manage questions, problems and issues arising from customers or even internal employees. Helpdesk services have become an integral part of an organization's wider service function. The importance of helpdesk services in a modern organization should not be underestimated. They help organizations deal with issues and problems that left unresolved can lead to financial loss and generate negative publicity. Successful helpdesk solutions have been attributed to helping organizations run more smoothly and to providing a higher quality of support to customers.

Developing and implementing a helpdesk solution, however, is not a trivial undertaking. Helpdesk solutions require the coordination of resources, both physical and human, as well as the coordination of data, information and knowledge. In addition, helpdesk services rely on a complex underlying telecommunications infrastructure. The primary media utilized in helpdesk services is still the telephone. The structure of many of these systems is a call center manned by customer service agents with access to computer systems employing specialized software. In order to maintain a successful helpdesk service, an organization must manage both the specific knowledge-base of the product or services for which support is provided and the helpdesk system itself.

The benefits of helpdesk solutions have lead to worldwide growth in demand for call centers and customer service agents. As many medium and small-sized businesses cannot afford to setup and maintain an in-house call center or support call center operations that span multiple locations, the business of offering outsourced helpdesk 
services is at record levels. Major corporations such as Hewlett Packard, IBM, and Dell, who maintain large helpdesk facilities, located around the world, have identified a business opportunity - that of offering the utilization of their existing call centers to smaller companies who may be financially unable to extend their current call routing infrastructure. Organizations who offer contractual helpdesk services utilize their pre-established worldwide call routes to provide call routing to other organizations. They also offer co-use of their facilities which opens the market to helpdesk resources and customer service agents in areas where lower wages offer cost-savings potential.

As the growth trend continues, organizations who offer contractual helpdesk services, also known as call center outsourcing, will be faced with even greater challenges as they move to one-stop customer service providers who offer full solution packages. The new and upcoming group of contractual helpdesk service providers will also need to take into consideration that they are entering an emerging market and one that is poised for change. According to Datamonitor, an independent market analyst, in their report, 2007 Trends to Watch: Contact Center Outsourcing and Services, "the evolution of horizontal functions will also challenge contact center outsourcers, as more investors move toward one-stop-shops for multiple services. In addition, technological shifts will be an area of concern for outsourcing vendors, as end-users rapidly adopt new and sophisticated contact channels" (Dawson, 2007, p. 12). Voice telephony will remain the primary contact channel but additional channels such as Web-chat and SMS are gaining in popularity. The growth in technology makes it imperative for businesses who offer contractual helpdesk services to remain knowledgeable about newly available solution options to insure they are able to offer their clients the best services possible. Further, while the trend is towards one-stop-shops, it is also towards tailored solutions. According to Datamonitor (Dawson, 2007), "If outsourcing vendors are to maintain and increase vertical market share, tailored solutions for individual markets will be required, which will also have to take into account multi-channel capabilities" (p.12)

Many organizations choose to utilize contractual helpdesk services rather than develop in-house solutions so they can focus on core areas of their business. To implement an in-house service, a business needs a department or, at least, an individual whose primary responsibility is to insure that technological advances in telephony hardware and software components and advancements in routing techniques are adequately reflected in the helpdesk operations. A business whose primary focus is not helpdesk services might find this an unnecessary cost and unable to justify this expense as it is not considered a revenue generator for the company.

The primary reason, however, that organizations enlist contractual helpdesk services is cost-driven. As with any outsourcing contract, the primary objectives are to select an appropriate vendor and prepare a detailed contract that meets the needs of both parties. The contract should be devised using a systemic and thorough process that results in the articulation of service level agreements mapped to specific functions and services. While, the basic principles for negotiating an outsourcing contract apply, there are special considerations that must be made when contracting for outsourced helpdesk services. These considerations include determining an optimal solution by mapping business requirements to specific call center resource options, determining the optimal call routing structure given budgetary considerations, understanding the technical problems associated with the call center environment and developing a satisficing plan to address these problems should they occur.

\section{Optimal Contractual Helpdesk Service Solutions}

According to David Tropio, Call Center Consultant for Hewlett Packard, in order to provide the best call center service solution, one has to first determine basic needs and constraints. These include considerations such as the number of agents needed, budget limitations and the cost of implementation. The cost for support also needs to be assessed. These costs will depend upon the physical location of the call center. For instance, in the United States, the vendor may own the infrastructure (telecommunications and networking), reducing variability in support costs. Infrastructure support and cost stability is sometimes a concern in other countries. Further, the totality of service must be assessed. The usual range of options include vendor hosted to vendor hosted, supported and managed. In most cases, a vendor supported as well as vendor managed solution is chosen. This is often more cost effective as the vendor knows their system which offsets training costs to the client who assumes management responsibilities for their helpdesk services. 
A major area of consideration is determining the number of agents needed to answer calls and how many site locations are desired. “...customers couldn't care less if [one has] one or many locations or if [there are] phone switches or IVR systems from a variety of manufacturers. All they care about is making sure they speak with agents who can help them" (Fleischer, 2001). Determining site locations is based on how well sites are able to support each other. For example, there are cases when more than one site will support the same type of calls as another site; there are also instances where the helpdesk application offers various menu options that route calls to different site locations. An application for the purposes described here is mapped to an 800, 888, 866, or 877, or otherwise tollfree number prefix. An application includes all of the menu options available for a specific prefix as well as the routing configuration, including exit points, take back and transfer codes, if needed. Sites that support each other include additional options for how calls are routed. Tim Toone, Senior IT Business Consultant at Hewlett Packard, states that a rule of thumb is to only provide a $4 \times 4$ menu such that no more than four options are offered and no more than four submenu options are included.

Even if multi-sites are not utilized, a business decision has to be made in regards to routing to call center agents and whether calls are routed to call center agents with certain skills, or whether all agents take all calls. This will determine how many options are placed on the application menu and, ultimately, how many agents will actually be needed. Skills, also referred to as a hunt group or a characteristic that can be linked to an individual or a group of individuals, dictates where a call is routed. Calls may be routed via a vector, a specific set of steps that link a call to a skill. Using a vector approach, calls are mapped to an internal Virtual Dialed Number (VDN) that determines what calls are linked to which vector. Basically the calls are mapped based on the service the caller desires (billing, customer service, etc.) The vector is comprised of a set of processing commands that result in the routing of the call. Once this basic set of decisions has been made, a cost breakdown analysis can be made. This analysis specifies the cost of any necessary equipment, software, training, per minute costs per call, and the costs for additional phones. David Tropio states that a typical contract with about 25 agents typically cost about $\$ 10$ million all inclusive, garnering a net income for the solution provider of about $\$ 4.6$ million. Given the high cost of such a venture, it is imperative that business needs are mapped to the most cost-effective but yet optimal helpdesk service solution.

\section{Transporting Calls}

Transporting calls, or the way in which calls are routed, is one of the most important considerations made in securing helpdesk services. Various routing options are available and option chosen should be based on business requirements and budgetary constraints. Routing options include skills based routing, next available agent routing, percentage based routing and more complex methods implemented dynamically. Additional considerations must be also be made if the call center is located outside the US. In order to route calls internationally, an international toll free number must be obtained as some countries do not support call made to toll-free prefixed numbers in the US. An international toll free number is a very costly option.

For larger organizations who offer multiple products and services, skill based routing (SBR) is a necessity. In a call center environment, skill based routing allows a call to be routed to an agent that is trained to respond to that type of call. In SBR, customer requirements are evaluated based on such traits as language preference, product type, or even customer buying behavior. With this option, an interactive voice response system can ask customers to identify themselves through screen pops, a telephony software application that allows the agent to see the type of call and also provides information about the caller prior to answering the call. The system uses this information to compare against the customer profile database in order to route the call. The basic goal of SBR is to provide an "automated mechanism for routing calls to find the best available match between the needs of the customer and various proficiencies of available agents. Skills-based routing is an ideal solution for providing callers with a quality experience in an automated manner" (Special TMC labs review, 2000, p. 104). According to L'Ecuyer (2003), SBR provides many benefits for it "...allows a company to be proactive in meeting customer requirements and expectations, to increase service levels while decreasing wait time, and to use real-time statistics to aid in routing the call - all of which can lead to increased profitability" ( p. 64). 
In many ways, the opposite of SBR would be static routing where any available agent takes the call. This is basically a next available agent approach. Static routing typically does not include any form of skill based routing nor does it include any controlled allocations for routing. Basically it is used for call centers that have an application loaded or an option, when chosen, that routes to a location where every agent is skilled to take the call. Static routing is more concerned about load distribution and emptying queues in order to connect callers to agents as soon as possible. Using this option, customers are typically identified through the number they called from or the number they dialed. This is, of course, the least costly option for a business. However cost savings may be offset by extra training costs needed to insure that the customer experience is not reduced ( L'Ecuyer, 2003).

Another form of routing is called percentage based routing or onboard routing. In the standard sense, this is static routing based on percentages. This form of routing was created to allow for multiple locations to take calls to prevent any one location from becoming overloaded. For instance, Call Center A might be assigned to accommodate 50\% percent of the calls while Call Center B takes $20 \%$ and Call Center C takes the other 30\%. Each location receives calls concurrently but only to their percentage allocation. This method of routing is very helpful especially when utilized for backup or disaster recovery purposes. It is also helpful if a site has a limited number of agents but needs additional capabilities during peak times. Percentage based routing can also be implemented dynamically so that percentage allocations can change based on time of day.

Dynamic routing, which is used to ensure calls are routed in a timely fashion, can be configured based on multiple variables including number of agents, number of sites and time-of-day. It can even utilize both skill and percentage based routing. Controlled allocations can be placed on dynamic routing for routing to the Longest Available Agent (LAA) or the Minimum Expected Delay (MED) based on the minimum time the caller will have to wait. With time-of-day allocation, calls might be routed, for example, to Call Center A from $8 \mathrm{am}-5 \mathrm{pm}$ and to Call Center B from 5:01 pm until 7:59 am. Call Center B may be located in a different time zone accommodating normal working hours for its staff. Call types may also be categorized facilitating dynamic routes meaning that calls can be taken at different site locations using the same or different skill numbers. Dynamic routing is the most expensive form of routing but also the most efficient.

Determining which form of routing to use is entirely a business decision. Static routing is the most cost effective but dynamic routing is the most preferred. Contractual helpdesk service providers need to insure clients know the pros and cons of each option and provide them with examples of what the customer experience will be like. This gives clients the information they need to choose the option which is most viable for them. Toledo (1996) recommends a set of five rules to apply before 'rushing into a decision on call routing technology.' These rules include: 1) Look at the forest, not the trees by insuring the option under investigation provides intelligence and flexibility in setting up call routing rules; 2) Be aware that locking into one source may lock you out of using multiple carriers' networks; 3) Manage the total system and measure results; 4) Realize that 'the next available agent' is not always the best available answer; and 5) Look for simplicity and robustness.

\section{Addressing Technical Problems}

Within a call center environment, technical problems are a real possibility. Technical problems can arise at several levels from application failure, to an inability to handle call volume spikes to an event where the call center, itself, goes down. There are strategies for dealing with these issues but each approach has associated costs. For instance, standards exist for dealing with the disastrous situation of a call center site going down. The standard calls for a preconfigured backup site to be in place to which $100 \%$ of the calls can be automatically rerouted. While the can be achieved with ease using skill based and dynamic based routing, the associated costs can be substantial.

The level of support service provided by the contracted call center is also a consideration. Technical issues are often higher if a call center does not employ advances in technology such as computer telephony integration (CTI). CTIs are specifically designed to address and resolve technical issues. They provide a control link between the telephone and the computer allowing the two systems to 'talk to each other.' The CTI simultaneously delivers voice and data to the desktop and also tracks events taking place during every call (Smith, 1996). Most call centers utilize software applications, so just as in any IT environment issues may occur with the operating systems, 
applications, and even the routing processes. The data collected by the CTI is maintained in a file on the host computer. The CTI uses the data it processes to contact technical support if a system interruption occurs. The provision of this type of support should be explicitly sited in an outsourced helpdesk services contract.

In addition to application failure, issues with call routing may also occur. The more ACDs (Automatic Call Distribution) installed, the more complicated call routing becomes. ACDs typically route on a first-come-first-serve basis which is inefficient when call volume increases or spikes. Networked ACDs alleviate problems arising from high call volumes by shifting calls from one location to another when queues are long and response times slow. More intelligent management software and skill based routing can be used to determine, in real-time, most efficient patterns for call routing (Toledo, 1996).

According to Saul (1999), another solution to technical problems arising from high call volume can be addressed by the use of a web based ACD system. A major issue related to helpdesk call centers is that agents have to wait for a customer to complete the tasks needed to process a request making the typical ACD lose its efficiency, especially if it is the only source of communication used during a support call. The traditional ACD environment assumes that an agent can only help one customer at a time. Web-based ACD's allow for agents to handle concurrent customer requests as they are able to 'show and tell' information with the customers. Basically with this technology a customer can review web based documentation, while the agent assisting them works with another customer.

As previously stated most call center technical problems can be avoided through workforce management techniques, providing the best solution for the call center environment including routing techniques and utilizing monitoring technology solutions put in place in the event a crisis occurs. Technology constantly changes but determining the best way to avoid technical issues is in knowing and understanding the individual call center environment and insuring that the best and most cost-efficient solutions are utilized.

\section{Decision Model For Contracting Helpdesk Services}

Contractual helpdesk service offerings will continue to grow. For many companies, outsourcing helpdesk services provides the most optimal solution. However, entering into these types of agreements should be done with much forethought and planning. Figure 1 represents a pictorial view of the decisions that should be investigated prior to entering into a contractual helpdesk service agreement. Fundamentally all decisions should be predicated on business needs and mapped to budgetary realities. Then appropriate service options including number of agents needed, routing and backup allocations can be assessed. Once pre-decisions have been made, a contracted helpdesk vendor chosen and the services implemented, management of the contractual helpdesk service agreement must remain an ongoing task which requires constant monitoring and evaluation. 


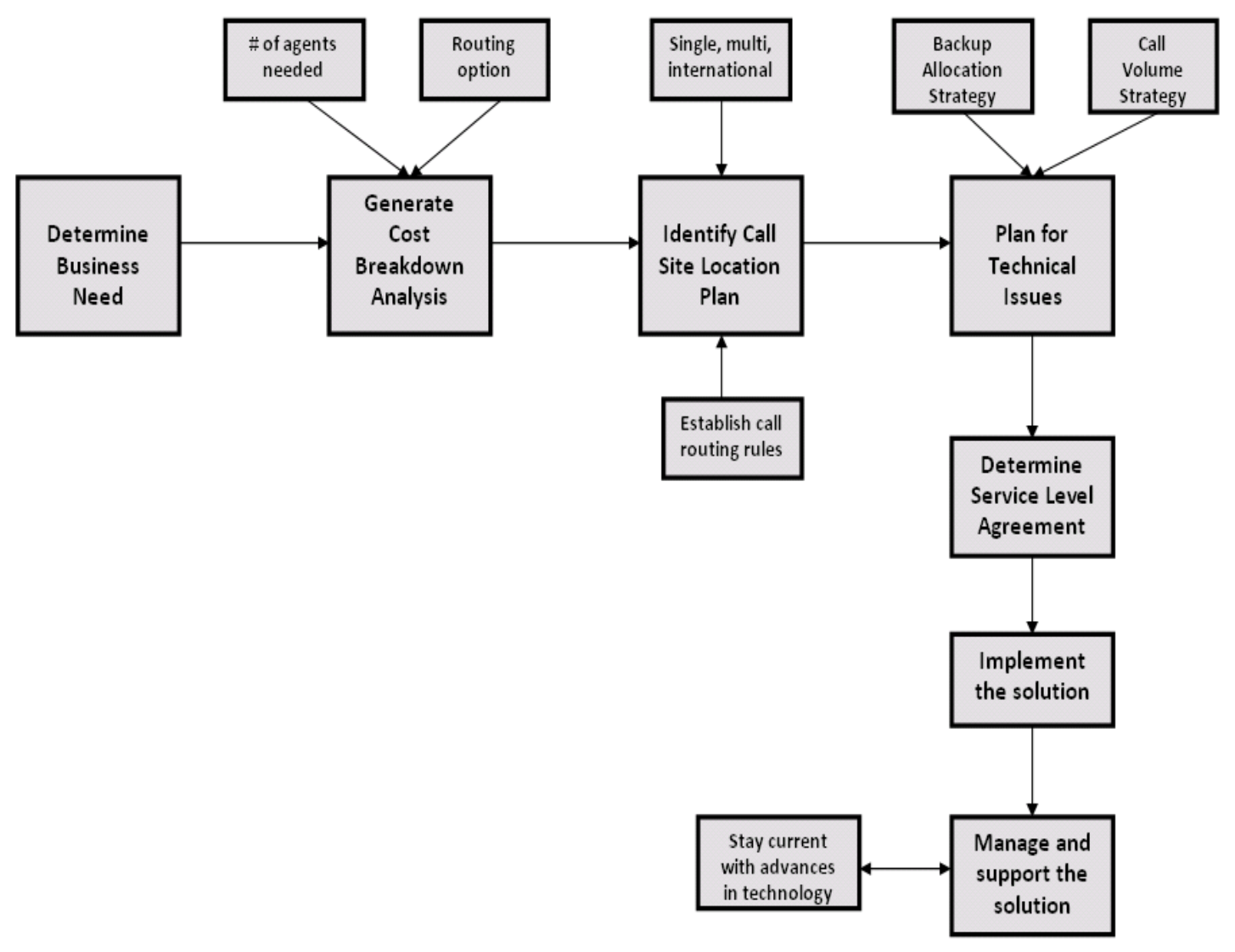

Figure 1: Contractual Helpdesk Service Agreement Decision Flow

\section{CONCLUSION}

Contractual helpdesk services is a growing trend. Already, according to industry statistics, $5 \%$ of North America's 60,000 contact centers are outsourced and of the 3.3 million agent positions, $10.5 \%$ are outsourced ("Call center savings available", 2007). Advances in telecommunications technology has been a major factor in the rapid expansion of helpdesk service outsourcing. It has extended call center capabilities improving routing options and providing flexibility in establishing call center site locations. At the same time, these advances translate into higher resource costs for maintaining in-house helpdesk services. Many organizations do not have the resources to establish globally-based call centers nor to dedicate employees for the sole purpose of acquiring and maintaining the advanced skills needed to design, implement and maintain complex routing protocols. Further, as call centers become more customer focused, the complexity of the technology increases to meet customer expectations. The technology is changing so rapidly that it will require effective and efficient management of the applications and services in order to retain customers and maintain strong customer relationships. On the other hand, the advances have created opportunities. As L'Ecuyer (2003) points out, "Call centers used to be considered cost centers; companies now see the potential of turning their contact centers into profit centers. Contact centers are now used much more as strategic elements in running a business" (p. 64). This means offering helpdesk service solutions has 
the potential to generate profits as well as offer a high return on investment. There are several potential winners in this scenario. Organizations maintaining existing call center facilities with extra capacity are able to extend their service offerings to include contractual helpdesk solutions. Organizations, which do not desire to or cannot afford to establish and maintain their own call center infrastructure, have options to outsource those options. Whatever the case, contract helpdesk service vendors and clients must remain diligent implementing best practices is what contract helpdesk service vendors and clients must adhere to in order to insure optimal solutions are implemented.

\section{REFERENCES}

1. $\quad$ Call center savings available. (2007). Communications News 44 (5) 8.

2. Dawson, K. (2007). Datamonitor Details Trends in Outsourcing. Call Center Magazine, 20 (5), 12, Retrieved June 25, 2008 from http://www.callcentermagazine.com/shared/article/showArticle.jhtml?articleId=197801260

3. $\quad$ Fleischer, J. (2001) A mecca for customers' calls. Call Center Magazine, 14 (6), 67-73.

4. L'Ecuyer, M. (2003, May). Using skills-based routing to enhance contact center revenue and performance. CustomerInter@ction Solutions, 21 (11)64-67.

5. Saul, M. and Taibl, A. (1999). Managing multimedia interactions demands attention to routing. Call Center Solutions, 17 (8), 88-94.

6. Smith, G. (1996). High-tech companies exploit full range of CTI capabilities to bolster customer service. Telemarketing \& Call Center Solutions, 14 (8), 80-81.

7. Special TMC labs review: Skills-based routing: Matchmaking and the call center, part I. (2000, April). Call Center CRM Solutions 18 (10), 104-116, Retrieved June 25, 2008 from http://findarticles.com/p/articles/mi_qa3973/is_200004/ai_n8902017

8. Special TMC labs review: Skills-based routing: Matchmaking and the call center, part II. (2000 May). Call Center CRM Solutions, 18 (11), 94-100, Retrieved June 25, 2008 from http://findarticles.com/p/articles/mi_qa3973/is_200005/ai_n8891038/pg_1?tag=artBody;col1

9. Toledo, Leo (1996, February). Call routing technology: The key to sophisticated, flexible workforce management. Telemarketing \& Call Center Solutions, 14 (8), 76.

\section{AUTHOR INFORMATION}

Meg Murray is an Associate Professor of Information Systems in the Department of Computer Science and Information Systems at Kennesaw State University, Kennesaw, GA. Dr. Murray specializes in the area of emerging technologies and the development and implementation of those technologies to meet business and organizational needs. Her most current work in this area has been focused on the technical and societal implications of the evolving software paradigm referred to as 'Software as a Service.'

Joy Young received a Masters Degree in Information Systems from Kennesaw State University. She has spent several years in the IT profession and has recently been involved in identifying best practice approaches to assist clients exploring contractual helpdesk services. 
NOTES 